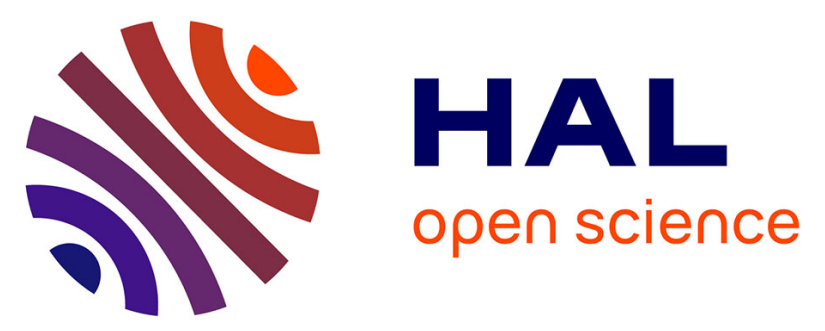

\title{
Heteroleptic Lanthanide Complexes Coordinated by Tripodal Tetradentate Ligand: Synthesis, Structure, and Magnetic and Photoluminescent Properties
}

Jérome Long, Dmitry Lyubov, Tatyana Mahrova, Konstantin A. Lyssenko, Alexander Korlyukov, Yury Fedorov, Ekaterina Yu. Chernikova, Yannick Guari, Joulia Larionova, Alexander A. Trifonov

\section{To cite this version:}

Jérome Long, Dmitry Lyubov, Tatyana Mahrova, Konstantin A. Lyssenko, Alexander Korlyukov, et al. Heteroleptic Lanthanide Complexes Coordinated by Tripodal Tetradentate Ligand: Synthesis, Structure, and Magnetic and Photoluminescent Properties. Crystal Growth \& Design, 2020, 20 (8), pp.5184-5192. 10.1021/acs.cgd.0c00410 . hal-02919790

\author{
HAL Id: hal-02919790 \\ https://hal.science/hal-02919790
}

Submitted on 27 Nov 2020

HAL is a multi-disciplinary open access archive for the deposit and dissemination of scientific research documents, whether they are published or not. The documents may come from teaching and research institutions in France or abroad, or from public or private research centers.
L'archive ouverte pluridisciplinaire HAL, est destinée au dépôt et à la diffusion de documents scientifiques de niveau recherche, publiés ou non, émanant des établissements d'enseignement et de recherche français ou étrangers, des laboratoires publics ou privés. 


\title{
Heteroleptic lanthanide complexes coordinated by
}

\section{tripodal tetradentate ligand: synthesis, structure,}

\section{magnetic and photoluminescent properties}

\author{
Jérôme Long*, ${ }^{a}$ Dmitry M. Lyubov, ${ }^{b, c}$ Tatyana V. Mahrova, ${ }^{b}$ Konstantin A. Lyssenko, ${ }^{c, d}$ \\ Alexander A. Korlyukov, ${ }^{c}$ Yury V. Fedorov, ${ }^{c}$ Ekaterina Yu. Chernikova, ${ }^{c}$ Yannick Guari, ${ }^{a}$ Joulia \\ Larionova, $^{a}$ and Alexander A. Trifonov ${ }^{* b, c}$ \\ a. ICGM, Univ. Montpellier, CNRS, ENSCM, Montpellier, France. \\ b. Institute of Organometallic Chemistry of Russian Academy of Sciences, 49 Tropinina str., \\ GSP-445, 630950, Nizhny Novgorod, Russia. \\ c. Institute of Organoelement Compounds of Russian Academy of Sciences, 28 Vavilova str., \\ 119334 , Moscow, Russia. \\ d. Lomonosov Moscow State University, Dept. Chem., Leninskie Gory 1, Build 3, Moscow \\ 119991, Russia.
}


We report the synthesis, structures, magnetic and luminescent properties of a series of heteroleptic lanthanide complexes based on a tripodal tetradentate ligand $\left[\operatorname{Ln}(\mathrm{Tpma})\left(\mathrm{NO}_{3}\right)_{3}\right] \cdot n \mathrm{MeCN}(\operatorname{Ln}=\mathrm{Eu}(\mathbf{1}), \mathrm{Tb}(\mathbf{2}), \operatorname{Dy}(3), \operatorname{Er}(4), n=0.5 ; \mathrm{Yb}(\mathbf{5}), n=0 ; \mathrm{Tpma}=$ tris((1H-pyrazol-1-yl)methyl)amine). The europium, terbium and dysprosium analogues exhibit a lanthanide-based luminescence, while dysprosium, erbium and ytterbium compounds show a field-induced slow relaxation of their magnetization involving Raman and direct processes.

\section{Introduction}

Single-molecule magnets (SMMs) based on lanthanide ions have recently emerged as new exciting molecular objects due to their fascinating magnetic properties offering interesting potentialities in high-density information storage or quantum computing. ${ }^{1-4}$ The occurrence of a slow relaxation of the magnetization, which is usually associated with a magnetic bistability at the molecular scale is highly dependent of the congruous combination between a lanthanide ion and the surrounding ligands to allow maximizing the magnetic anisotropy inherent to the $4 f$ ion. Hence, this synergistic effect creates a large crystal-field splitting that generates an anisotropic barrier, $\Delta$, separating two opposite magnetic states with a subsequent superparamagnetic-like behavior. An efficient SMM aims a high multistep energy barrier involving as many doublet states as possible by its multiplet structure and suppression of other undesirable relaxations, such as Quantum Tunneling of Magnetization (QTM) and Raman. ${ }^{2,5-9}$ With this in hands, numerous lanthanide complexes with considerable anisotropic barriers have been recently reported, ${ }^{7,}$ 10-13 with the milestones belonging to the dysprosium metallocene family showing a high temperature hysteresis, ${ }^{12,14,15}$ that for some complexes even exceed liquid nitrogen's boiling temperature. ${ }^{16}$ 
However, the examples of non-organometallic high performance lanthanide SMMs based on classical ligands involving nitrogen and/or oxygen atoms are still relatively scarce. ${ }^{10,17-23}$

In this sense, we have recently reported the synthesis and magnetic properties of a series of original heteroleptic lanthanides complexes $\left[\operatorname{Ln}(\mathrm{Tpm}) \mathrm{X}_{3}\right](\mathrm{Ln}=\mathrm{Tb}$, Dy, Er; Tpm $=\operatorname{tris}(3,5-$ dimethylpyrazolyl)methane; $\mathrm{X}^{-}=\mathrm{NO}_{3}{ }^{-}, \mathrm{Cl}^{-}$) based on a tripodal tris(pyrazolyl)methane ligand. ${ }^{24}$ These complexes exhibit a field-induced slow relaxation of the magnetization which is highly dependent on both, the lanthanide ion's and counter anion's nature. Such complexes and others obtained by utilizing others six electron donor ligands such as the negatively charged tris(pyrazolyl)borate $(\mathrm{Tp})^{25-29}$ or tris(pyrazolyl)methane $(\mathrm{Tpm}),{ }^{24,30}$ constitute an interesting family of SMMs where the steric hindrance and the electronic density of ligands may be adjusted through the substituent groups of pyrazolyl and the central atom (carbon or boron). In comparison, the family of tris(pyrazolyl)methylamine ligands (Tpma) based on the tripodal tris(2-aminoethyl)-amine (tren) has received far less attention in coordination chemistry of transition metals and lanthanide ions, ${ }^{31-34}$ despite their several interesting features. In fact, the peripheral functionalization of the tren moiety may allow to finely tune both, the steric and electronic features. Moreover, its strongly chelating ability associated with the rigid backbone may reduce the molecular vibrations (metal-ligand modes) that are known to enhance Raman relaxation and in turn decrease the magnetic potentialities. ${ }^{9,14,16,35}$ For these reasons, such ligands should afford a different coordination environment with the respect to the previously considered ones and could in turn alter the slow relaxation features. In addition, these ligands present also an interesting potential with the aim to introduce others functionalities besides magnetism, such as luminescence or redox activity. ${ }^{36,37}$ However, to the best of our knowledge, examples of lanthanide complexes based on such ligands are relatively scarce, ${ }^{34}$ while only a few 
lanthanide SMMs based on the tripodal $C_{3}$ tren ligand derivatives such as Schiff bases have been published. $^{38-41}$

Following this, we report in this article the synthesis, structures, magnetic and photoluminescent properties of a series of lanthanide ion complexes based on an original tripodal tetradentate Tmpa ligand. Depending on the nature of the lanthanide ion, slow relaxation of the magnetization could be evidenced for all Kramers ions, while typical lanthanide luminescence is exhibited for the europium, terbium and dysprosium analogues.

\section{Experimental Section}

\section{Materials and Methods}

The synthesis of complexes 1-5 was performed under aerobic conditions. Acetonitrile was distilled prior to use. Tris((1H-pyrazol-1-yl)methyl)amine) (Tpma) was prepared according to the literature procedure. ${ }^{31}$ IR spectra were recorded as Nujol mulls on a Bruker-Vertex 70 spectrophotometer. The $\mathrm{C}, \mathrm{H}, \mathrm{N}$ elemental analyses were carried out in the microanalytical laboratory of the IOMC by means of a Carlo Erba Model 1106 elemental analyzer with an accepted tolerance of 0.4 unit on carbon $(\mathrm{C})$, hydrogen $(\mathrm{H})$, and nitrogen $(\mathrm{N})$. Lanthanide metal analysis was carried out by complexonometric titration. ${ }^{42}$ Thermogravimetric analysis was performed on a Perkin Elmer Pyris-6 TGA equipment with a heating speed of $5{ }^{\circ} \mathrm{C} . \mathrm{min}^{-1}$ for all complexes 1-5.

\section{Synthesis of $\left[\mathrm{Ln}(\mathrm{Tpma})\left(\mathrm{NO}_{3}\right)_{3}\right] \cdot n \mathrm{MeCN}$}

[Eu(Tpma)(NO $\left.\left.)_{3}\right)_{3}\right] \cdot \mathbf{0 . 5} \mathrm{MeCN}(\mathbf{1}): \mathrm{MeCN}(30 \mathrm{~mL})$ was added to a mixture of $\mathrm{Eu}\left(\mathrm{NO}_{3}\right)_{3}\left(\mathrm{H}_{2} \mathrm{O}\right)_{6}$ $(0.410 \mathrm{~g}, 0.919 \mathrm{mmol})$ and slight excess of Tpma $(0.260 \mathrm{~g}, 1.011 \mathrm{mmol} ; 1.1$ equivalent $)$ and the resulting suspension was heated at $80^{\circ} \mathrm{C}$ for $10 \mathrm{~min}$ to give a clear pale yellow solution. The 
solution was concentrated by evaporation of the solvent at $80{ }^{\circ} \mathrm{C}$ approximately to half of the initial volume. Cooling the solution to room temperature resulted in the formation of $\mathbf{1}$ as colorless crystals. The mother liquid was decanted and the crystals were washed twice with $\mathrm{MeCN}(5 \mathrm{~mL})$. Crystals of 1 were dried in vacuum for $10 \mathrm{~min}$.

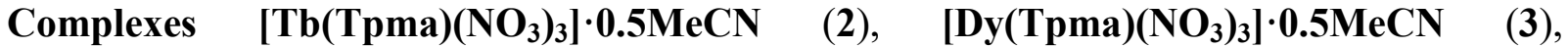
$\left[\operatorname{Er}(\mathrm{Tpma})\left(\mathrm{NO}_{3}\right)_{3}\right] \cdot 0.5 \mathrm{MeCN}(4)$, and $\left[\mathrm{Yb}(\mathrm{Tpma})\left(\mathrm{NO}_{3}\right)_{3}\right]$ (5) were prepared following the similar procedure and were isolated as colorless (2, 3, and 5) or pale pink (4) crystals. Complexes 1-5 were isolated in 70, 76, 83, 72 and 65\% yields respectively. Complexes 1-4 crystallize as solvates $\left[\mathrm{Ln}(\mathrm{Tpma})\left(\mathrm{NO}_{3}\right)_{3}\right] \cdot 0.5 \mathrm{MeCN}$ or as $\left[\mathrm{Yb}(\mathrm{Tpma})\left(\mathrm{NO}_{3}\right)_{3}\right]$ for $\mathbf{5}$.

Characterization of $\left[\mathrm{Eu}(\mathrm{Tpma})\left(\mathrm{NO}_{3}\right)_{3}\right] \cdot \mathbf{0 . 5 M e C N}(1)$ : Elemental analysis calcd. (\%) for $\mathrm{C}_{13} \mathrm{H}_{16.5} \mathrm{~N}_{10.5} \mathrm{O}_{9} \mathrm{Eu}: \mathrm{C}, 25.36 ; \mathrm{H}, 2.70 ; \mathrm{N}, 23.88 ; \mathrm{Eu}, 24.68$; found (\%): C, 25.54; H, 2.93; $\mathrm{N}$, 24.07; Eu, 24.42. IR (Nujol, KBr) v/cm $\mathrm{cm}^{-1}: 505$ (m), 525 (m), 610 (s), 650 (s), 745 (s), 770 (m), $780(\mathrm{~m}), 795$ (s), 815 (s), $860(\mathrm{w}), 880(\mathrm{~s}), 900$ (w), 920 (s), 955 (s), 980 (s), 1005 (w), $1030(\mathrm{~m})$, $1045(\mathrm{~m}), 1065$ (m), $1100(\mathrm{w}), 1150(\mathrm{~s}), 1195(\mathrm{~m}), 1210(\mathrm{w}), 1295$ (s), $1515(\mathrm{~m}), 1680(\mathrm{~m}), 1740$ (w), $1775(\mathrm{w}), 1985(\mathrm{~m}), 2050(\mathrm{~m}), 2260(\mathrm{~m}), 2300(\mathrm{~m}), 2325(\mathrm{~m}), 2525(\mathrm{~m})$.

Characterization of $\left[\mathrm{Tb}(\mathrm{Tpma})\left(\mathrm{NO}_{3}\right)_{3}\right] \cdot 0.5 \mathrm{MeCN}(2)$ : Elemental analysis calcd. (\%) for $\mathrm{C}_{13} \mathrm{H}_{16.5} \mathrm{~N}_{10.5} \mathrm{O}_{9} \mathrm{~Tb}: \mathrm{C}, 25.07 ; \mathrm{H}, 2.67 ; \mathrm{N}, 23.62 ; \mathrm{Tb}, 25.52$; found (\%): C, 25.18; H, 2.59; N, 23.47; Tb, 25.45. IR (Nujol, KBr) v/cm $\mathrm{cm}^{-1}: 505$ (m), 525 (m), 610 (s), 650 (s), 745 (s), 770 (m), $780(\mathrm{~m}), 795(\mathrm{~s}), 815(\mathrm{~s}), 860(\mathrm{w}), 880(\mathrm{~s}), 900(\mathrm{w}), 920(\mathrm{~s}), 955(\mathrm{~s}), 980(\mathrm{~s}), 1005(\mathrm{w}), 1030(\mathrm{~m})$, 
$1045(\mathrm{~m}), 1065(\mathrm{~m}), 1100(\mathrm{w}), 1150(\mathrm{~s}), 1195(\mathrm{~m}), 1210(\mathrm{w}), 1295(\mathrm{~s}), 1515(\mathrm{~m}), 1680(\mathrm{~m}), 1740$ (w), $1775(\mathrm{w}), 1985(\mathrm{~m}), 2050(\mathrm{~m}), 2260$ (m), $2300(\mathrm{~m}), 2325(\mathrm{~m}), 2525(\mathrm{~m})$.

Characterization of $\left[\mathrm{Dy}(\mathrm{Tpma})\left(\mathrm{NO}_{3}\right)_{3}\right] \cdot 0.5 \mathrm{MeCN}(3)$ : Elemental analysis calcd. (\%) for $\mathrm{C}_{13} \mathrm{H}_{16.5} \mathrm{~N}_{10.5} \mathrm{O}_{9} \mathrm{Dy}: \mathrm{C}, 24.93 ; \mathrm{H}, 2.66 ; \mathrm{N}, 23.48$; Dy, 25.94; found (\%): C, 25.03; H, 2.69; N, 23.39; Dy, 25.80. IR (Nujol, KBr) v/cm-1: 505 (m), 525 (m), 605 (s), 650 (s), 745 (s), 765 (s), $780(\mathrm{~m}), 795$ (m), 815 (s), 865 (w), 890 (s), $910(\mathrm{w}), 920$ (s), 940 (m), $980(\mathrm{~s}), 1005$ (w), 1030 (s), $1045(\mathrm{w}), 1065(\mathrm{~s}), 1100(\mathrm{~m}), 1145(\mathrm{~s}), 1200(\mathrm{~m}), 1210(\mathrm{w}), 1290(\mathrm{~s}), 1500(\mathrm{~m}), 1690(\mathrm{w})$, 1735 (m), 1775 (m), 1985 (m), 2055 (m), 2250 (m), 2300 (m), 2320 (m), 2525 (m).

Characterization of $\left[\operatorname{Er}(\mathrm{Tpma})\left(\mathrm{NO}_{3}\right)_{3}\right] \cdot 0.5 \mathrm{MeCN}$ (4): Elemental analysis calcd. (\%) for $\mathrm{C}_{13} \mathrm{H}_{16.5} \mathrm{~N}_{10.5} \mathrm{O}_{9}$ Er: C, 24.74; H, 2.64; N, 23.30; Er, 26.50; found (\%): C, 24.83; H, 2.70; N, 23.39; Er, 26.40. IR (Nujol, KBr) v/cm ${ }^{-1}: 500$ (w), 530 (m), 605 (s), 650 (s), 745 (s), 770 (s), 785 (m), $795(\mathrm{~m}), 810(\mathrm{~s}), 865(\mathrm{~m}), 890$ (s), 910 (m), 920 (s), 945 (m), $980(\mathrm{~s}), 1005(\mathrm{w}), 1025$ (s), 1045 (w), 1065 (s), 1105 (m), 1150 (s), 1200 (m), 1210 (m), 1285 (s), 1505 (m), 1685 (w), 1735 (m), 1775 (m), 1985 (m), 2055 (m), 2260 (m), 2305 (m), 2330 (m), 2535 (m).

Characterization of $\left[\mathbf{Y b}(\mathbf{T p m a})\left(\mathbf{N O}_{3}\right)_{3}\right] \quad(\mathbf{5})$ : Elemental analysis calcd. (\%) for $\mathrm{C}_{12} \mathrm{H}_{15} \mathrm{~N}_{10} \mathrm{O}_{9} \mathrm{Yb}$ : C, 23.38; H, 2.45; N, 22.72; Yb, 28.08; found (\%): C, 23.61; H, 2.36; N, 22.92; Yb, 27.85. IR (Nujol, KBr) v/cm-1: 505 (w), 525 (m), 605 (s), 650 (s), 750 (s), 770 (s), 785 (m), $800(\mathrm{~m}), 815$ (s), $865(\mathrm{~m}), 895$ (s), 910 (m), 920 (s), 945 (m), $980(\mathrm{~s}), 1005$ (w), 1030 (s), 1045 (w), 1065 (s), 1105 (m), 1145 (s), 1200 (m), 1215 (m), 1280 (s), 1510 (m), 1680 (w), 1740 (m), 1780 (m), 1990 (m), 2055 (m), 2260 (m), 2300 (m), 2330 (m), 2535 (m). 


\section{Single-Crystal X-ray diffraction studies}

The data collection was with Bruker APEX-II CCD $\left[\lambda\left(\mathrm{Mo}_{\mathrm{K} \alpha}\right)=0.71072 \AA\right.$, $\omega$-scans $)$. The structures were solved by direct method and refined by the full-matrix least-squares technique against $\mathrm{F}^{2}$ in the anisotropic-isotropic approximation. Analysis of the Fourier density synthesis. Hydrogen atoms were placed in calculated positions and were refined in the "riding" model with $U(H)_{i s o}=1.2 U_{e q}$ of their parent atoms. All calculations were performed using SHELXTL-2017. Crystallographic data for the structures 1-5 were deposited at the Cambridge Crystallographic

Data Centre as supplementary no. CCDC 1989944-1989947 and 2006866. Crystal data and structure refinement parameters are listed in Table S1.

\section{Powder XRD studies.}

All powder XRD measurements were carried out with Bruker D8 Advance II diffractometer (sealed $\mathrm{Cu}$ tube, $\lambda[\mathrm{CuK} \alpha=1.5418 \AA]$, motorized slits) equipped with Lynx Eye detector at room temperature.

\section{Magnetic Measurements}

Magnetic susceptibility data were collected with a Quantum Design MPMS-XL SQUID magnetometer working in the range $1.8-350 \mathrm{~K}$ with the magnetic field up to 7 Tesla. The samples were prepared in a glove box. The data were corrected for the sample holder and the diamagnetic contributions calculated from the Pascal's constants. The AC magnetic susceptibility measurements were carried out in the presence of a 3 Oe oscillating field in zero or applied external DC field.

\section{Photoluminescence measurements}


The solid sample was sealed in a quartz tube in an argon atmosphere (glove box) using a Fluorolog-3-221 (HORIBA Jobin Yvon) spectrofluorimeter. The emission spectra were corrected for detection and optical spectral response of the spectrofluorimeter. The luminescence lifetime for solid complexes 1, 2 and $\mathbf{3}$ was determined at $295 \mathrm{~K}$ using a Fluorolog-3-221 spectrofluorimeter with a UV xenon flash lamp as an excitation source. The data was analyzed with OriginPro 2015 using single order exponential decay fitting.

\section{Results and discussion}

Synthesis and crystal structures. The equimolar reaction of rare-earth metal nitrates $\mathrm{Ln}\left(\mathrm{NO}_{3}\right)_{3}\left(\mathrm{H}_{2} \mathrm{O}\right)_{6}$ and Tpma (tris $((1 \mathrm{H}-$ pyrazol-1-yl)methyl)amine) in acetonitrile affords the heteroleptic complexes $\left[\mathrm{Ln}(\mathrm{Tpma})\left(\mathrm{NO}_{3}\right)_{3}\right] \cdot 0.5 \mathrm{MeCN}(\mathrm{Ln}=\mathrm{Eu}(\mathbf{1}), \mathrm{Tb}(\mathbf{2}), \mathrm{Dy}(\mathbf{3}), \mathrm{Er}(\mathbf{4})$ and $\left[\mathrm{Yb}(\mathrm{Tpma})\left(\mathrm{NO}_{3}\right)_{3}\right](\mathbf{5}$; see Experimental section). Slow cooling of concentrated MeCN solutions of complexes from $80^{\circ} \mathrm{C}$ down to room temperature resulted in the formation of crystals of $\mathbf{1}-\mathbf{5}$ in high yields. Attempts to prepare the related complexes containing two ligands per $\mathrm{Ln}^{3+}$ ion by reacting $\mathrm{LnX}_{3}\left(\mathrm{H}_{2} \mathrm{O}\right)_{n}\left(\mathrm{X}^{-}=\mathrm{NO}_{3}{ }^{-}, \mathrm{ClO}_{4}{ }^{-}, n=5,6 ; \mathrm{X}=\mathrm{Cl}^{-}, n=0\right)$ with excess of Tmpa in various solvents under rather harsh conditions failed. 

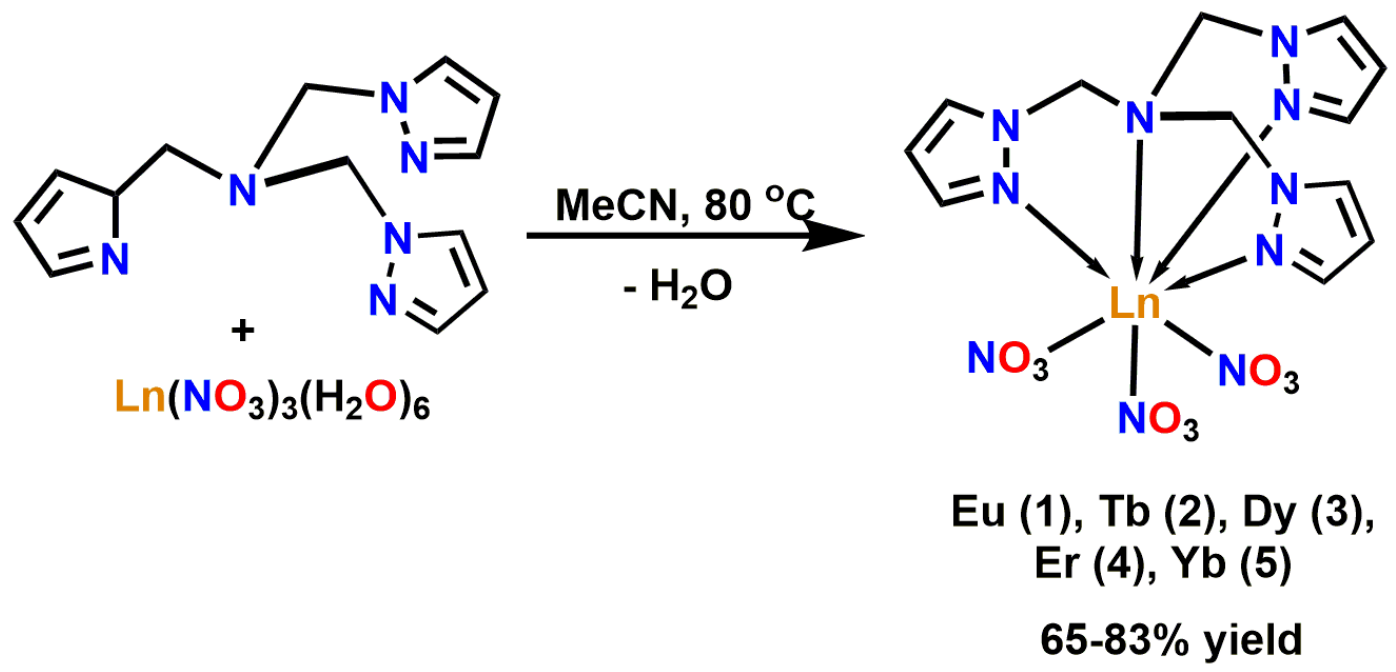

Scheme 1. Synthesis of complexes 1-5.

Analysis by single-crystal X-ray diffraction indicates that among the investigated compounds, 1-4 are isomorphous and crystallize in the triclinic $P \overline{1}$ space group (Table $\mathrm{S} 1$ ) as a solvate with a unique lanthanide complex and half of an acetonitrile molecule in the asymmetric unit. For clarity, only the structure of the dysprosium analogue $\mathbf{3}$ will be described in details, while bond length and angles for 1-5 are listed in Table 1 for comparison. The structure could be viewed as a mononuclear complex in which the $\mathrm{Dy}^{3+}$ ion is coordinated by four nitrogen from Tpma and six oxygens arising from three bidentate nitrate moieties giving a coordination number of 10 (Figure 1a). 


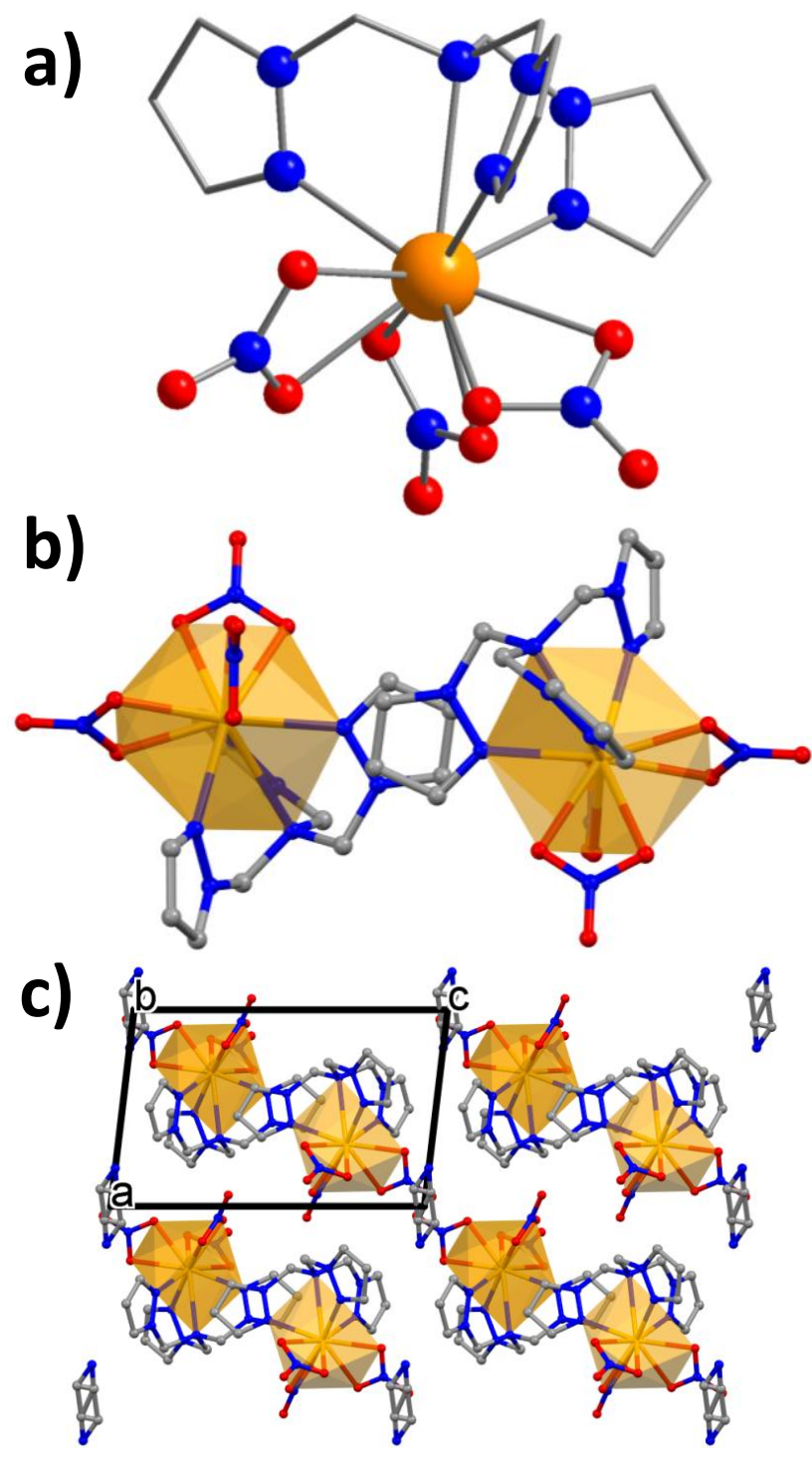

Figure 1. Molecular structure for complex 3. Colour code: orange, Dy; blue, N; red, O; grey, C. Hydrogen atoms have been omitted for clarity. b) Perspective view of $\mathbf{3}$ showing the $\pi$ stacking between two complexes. c) Perspective view of the crystal packing for 3 along the $b$ axis and showing the coordination polyhedra.

Quantitative analysis of the Dy ${ }^{3+}$ site's geometry using the SHAPE software ${ }^{43}$ indicates that it could be described as a distorted spherocorona (Table S2). The Tpma ligand coordinates to $\mathrm{Dy}^{3+}$ ion in a symmetrical fashion. The Dy-N distances involving the heterocyclic nitrogen atoms are 
ranging from 2.494(2) to 2.533(2) $\AA$ and are significantly shorter than the Dy-N distance from the central tertiary N amine of 2.767(2) $\AA$. On the other hand, the Dy-O distances have the values spanning from $2.433(2)$ to $2.502(2) \AA$. Note that this Dy-N(tertiary amine) distance in 3 is significantly longer than that of $2.680(2)$ in similar $\mathrm{Dy}\left(\mathrm{NO}_{3}\right)_{3}$ tris(benzimidazol-2ylmethyl)amine complex. ${ }^{34}$ Moreover, the average values of Dy-N (2.510 $\left.\AA\right)$ for heterocyclic nitrogen atoms and $\mathrm{Dy}-\mathrm{O}(2.469 \AA)$ in 3 are longer that those $(2.498$ and $2.423 \AA)$ in $\left[\mathrm{Dy}(\mathrm{Tpm})\left(\mathrm{NO}_{3}\right)_{3}\right]\left(\mathrm{Tpm}=\operatorname{tris}(3,5\right.$-dimethylpyrazolyl)methane $) .{ }^{24}$ The crystal packing analysis indicates that the shortest intermolecular Dy-Dy distance is equal to $8.268 \AA$, while hydrogen bonds involving the nitrates and hydrogens from the ligands as well as stacking interaction between pyrazoles (with the shortest $\mathrm{C} \cdots \mathrm{C}$ contact $c a .3 .39 \AA$ ) could be detected (Figure $1 \mathrm{~b}$ and c).

In contrast to $\mathbf{1 - 4}$, the $\mathrm{Yb}$ complex $\mathbf{5}$ crystallizes without any solvate molecules in the monoclinic $P 2_{1} / c$ space group (Table S1). Most likely, due to the lanthanide contraction and the consequent decrease of intramolecular distances leading to steric repulsions in the coordination sphere, only two nitrate anions are bidentate, while the remaining one is monodentate. As a result the coordination number of the $\mathrm{Yb}^{3+}$ ion in $\mathbf{5}$ is 9 , with a geometry of the $\mathrm{Yb}$ site which could be best described as a muffin with $C_{s}$ symmetry (Table S3). The geometry of Tpma ligand found in 5 differs significantly to those found in 1-4. Thus, two pyrazolyl rings of the Tpma ligand in 5 are almost coplanar (the dihedral angle between $\mathrm{N}_{\mathrm{Pyr}}-\mathrm{Yb}-\mathrm{N}_{\text {Amino }}$ is $170.0^{\circ}$ ), while the third pyrazolyl moiety is almost orthogonal relatively to two others (dihedral angles are 94.3 and $104.3^{\circ}$ ). For complexes 1-4, the dihedral angles between $\mathrm{N}_{\mathrm{Pyr}}-\mathrm{Yb}-\mathrm{N}_{\text {Amino }}$ planes lie within 114.1 $-129.0^{\circ}$. Moreover, the $\mathrm{Yb}-\mathrm{O}$ and $\mathrm{Yb}-\mathrm{N}$ distances in $\mathbf{5}$ are expectedly shorter with respect to the other analogues due to the lanthanide's contraction and the decrease of the coordination 
number. In particular, the $\mathrm{Yb}-\mathrm{N}$ distance with the central tertiary amine's nitrogen atom is equal to $2.708(3) \AA$. In contrast to $\mathbf{1 - 4}$, the only type of intermolecular interaction in the crystal is weak $\mathrm{C}-\mathrm{H} \cdots \mathrm{O}$ hydrogen bonds, while the shortest intermolecular $\mathrm{Yb}-\mathrm{Yb}$ distance is much shorter and equal to $7.425 \AA$. The change of the crystal symmetry from triclinic $P \overline{1}$ space group to monoclinic $P 2_{1} / c$ space group also induces a reduction in the volume accessible for solvents molecules.
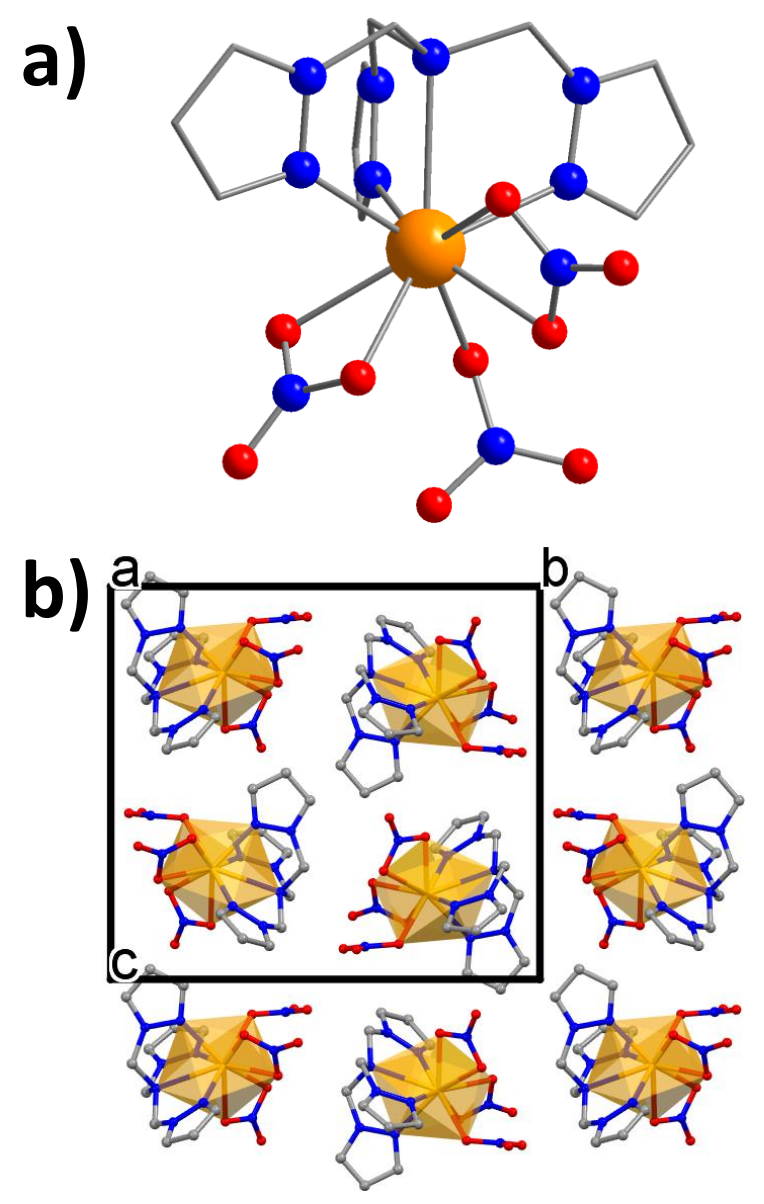

Figure 2. a) Molecular structure of 5. Colour code: orange, Yb; blue, N; red, O; grey, C. Hydrogen atoms have been omitted for clarity. b) Perspective view of the crystal packing for 5 along the $a$ axis and showing the coordination polyhedra. 
The purity of all samples were confirmed by Powder X-Ray Diffraction (Figures S1-S2), while the presence of acetonitrile molecules in the crystal packing of complexes 1-4 was established by thermogravimetric analysis (Figure S3). Hence, complexes 1-4 loose half an acetonitrile molecule in the temperature range $140-210^{\circ} \mathrm{C}$. The erbium complex 4 looses the acetonitrile at $140{ }^{\circ} \mathrm{C}$, while such desolvatation appears only at $200{ }^{\circ} \mathrm{C}$ for the europium analogue 1 . Further heating of the complexes up to $220-230{ }^{\circ} \mathrm{C}$ results in their decomposition. For 5 no evidence of an acetonitrile loss was observed, in accordance with the X-Ray structure, and only a complete decomposition at $235-245^{\circ} \mathrm{C}$ tooks place. 
Table 1. Selected bond distances and angles in complexes 1-5.

\begin{tabular}{lccccc}
\hline & $\mathbf{1}$ & $\mathbf{2}$ & $\mathbf{3}$ & $\mathbf{4}$ & $\mathbf{5}$ \\
\hline $\mathrm{M}-\mathrm{N}_{\mathrm{Pyr}}$ & $2.539(2)-2.567(2)$ & $2.507(2)-2.542(2)$ & $2.494(2)-2.533(2)$ & $2.470(2)-2.513(2)$ & $2.365(3)-2.453(3)$ \\
\hline $\mathrm{M}-\mathrm{N}_{\text {Amine }}$ & $2.793(2)$ & $2.774(2)$ & $2.767(2)$ & $2.756(2)$ & $2.708(3)$ \\
\hline $\mathrm{M}-\mathrm{O}\left(\kappa^{2}-\mathrm{NO}_{3}\right)$ & $2.470(2)-2.524(2)$ & $2.443(2)-2.509(2)$ & $2.433(2)-2.502(2)$ & $2.408(2)-2.493(2)$ & $2.346(3)-2.425(3)$ \\
\hline $\mathrm{M}-\mathrm{O}\left(\kappa^{1}-\mathrm{NO}_{3}\right)$ & - & - & - & - & $2.266(3)$ \\
\hline $\mathrm{N}_{\mathrm{Pyr}}-\mathrm{M}-\mathrm{N}_{\mathrm{Pyr}}$ & $94.9(1)-104.5(1)$ & $95.4(1)-104.8(1)$ & $95.5(1)-104.8(1)$ & $95.8(1)-104.9(1)$ & $95.8(1)-104.9(1)$ \\
\hline $\mathrm{N}_{\mathrm{Pyr}}-\mathrm{M}-\mathrm{N}_{\text {Amine }}$ & $61.1(1)-61.5(1)$ & $61.4(1)-61.8(1)$ & $61.4(1)-62.0(1)$ & $61.6(1)-62.2(1)$ & $61.6(1)-62.2(1)$ \\
\hline
\end{tabular}


Magnetic Properties. At the exception of the europium analogue 1, which is known to be diamagnetic at low temperature, the static (direct current, DC) and dynamic magnetic properties (alternate currents, AC) of other complexes were investigated by using a SQUID MPMS-XL.

DC Magnetic properties. The room temperatures $\chi T$ values of $12.97,13.92,11.54$ and 3.20 $\mathrm{cm}^{3} \cdot \mathrm{K} \cdot \mathrm{mol}^{-1}$ for $\mathbf{2}, \mathbf{3}, \mathbf{4}$, and $\mathbf{5}$, respectively are in a relatively good accordance with the theoretical values of $11.82,14.17,11.48$ and $2.57 \mathrm{~cm}^{3} . \mathrm{K} \cdot \mathrm{mol}^{-1}$ expected for a unique $\mathrm{Ln}^{3+}$ ion using the free-ion approximation. ${ }^{44}$ Upon cooling, all compounds exhibit the typical decrease of $\chi T$ caused by the thermal depopulation of the $m_{J}$ levels (Figure $3 \mathrm{a}$ ) to reach the values at $1.8 \mathrm{~K}$ of $5.25,7.35,4.98$ and $1.08 \mathrm{~cm}^{3} . \mathrm{K} \mathrm{mol}^{-1}$ for $\mathbf{2 , 3}, \mathbf{4}$, and $\mathbf{5}$, respectively. The field dependences of the magnetization at $1.8 \mathrm{~K}$ show values of $6.80,6.87,5.12$ and $1.91 N \beta$ under a $70 \mathrm{kOe}$ field for $\mathbf{2}, \mathbf{3}, \mathbf{4}$, and 5, respectively (Figure 3b). For all complexes, the lack of saturation for the magnetization curves point out the presence of magnetic anisotropy as expected for such lanthanide ions. ${ }^{6}$ 

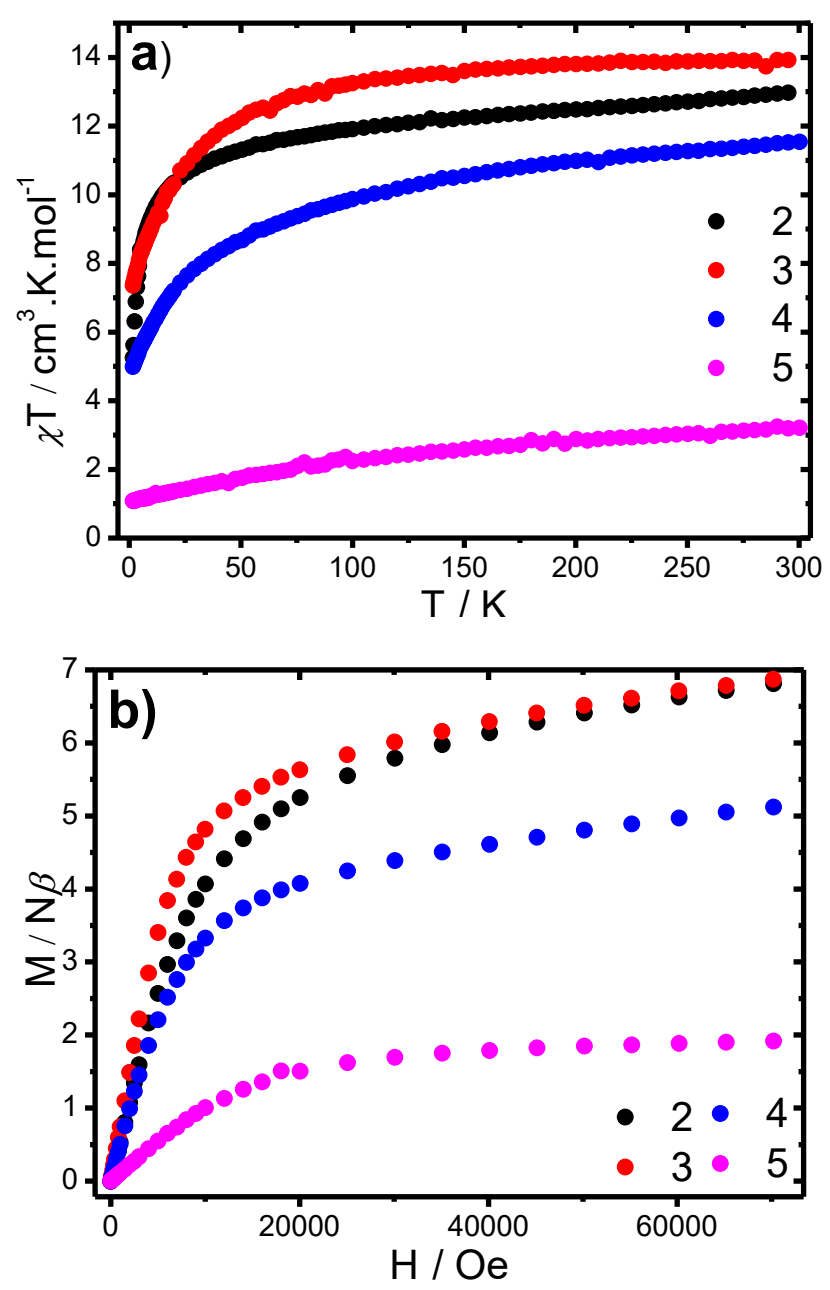

Figure 3. a)Temperature dependence of $\chi T$ measured under a 1000 Oe dc field for 2-5. b) Field dependence of the magnetization at $1.8 \mathrm{~K}$ for $\mathbf{2 - 5}$.

AC Magnetic properties. Alternate currents (ac) measurements were conducted to probe the occurrence of a slow relaxation of the magnetization. Under a zero-dc field, no strong out-ofphase susceptibility $\left(\chi^{\prime \prime}\right)$ components could be detected for all samples (Figure S4), which may be ascribed to occurrence of the fast QTM.

In order to decrease the QTM contribution, ac measurements were performed under various dc-fields. Except compound 2, for which the out-of-phase component remains weak, all the other complexes exhibit a strong $\chi$ ” component upon applying dc fields (Figure S4). Note that for both complexes $\mathbf{3}$ and $\mathbf{4}$, the appearance of a second low frequency peak could be observed at high 
magnetic fields. Due to the complexity in the slow relaxation in lanthanide complexes, the origin of these second peaks remains difficult to explain but might originate from different relaxation mechanisms actuated by large magnetic fields. From these data, extraction of the relaxation time related to the main peak, $\tau$, allows to study its field dependence (Figure S5) which could be modeled with the equation $\tau^{-1}=D H^{4} T+B_{1} /\left(1+B_{2} H^{2}\right)+K$ (Eq. 1) and for which the first term accounts for the direct process (for Kramers-ion), the second one stands for the QTM, while the $K$ constant accounts for the Raman and thermally activated processes. ${ }^{45-47}$ The fitting parameters could be found in Table S4. Note that it was however not possible to obtain a pertinent fitting for the erbium analogue 4 , which might be due to the presence of the second relaxation process that appear at high magnetic fields. The optimum field corresponding to the greatest relaxation time value for each complex is estimated at 500,250 and 1000 Oe for 3, 4 and 5, respectively. The frequency dependence of the ac susceptibilities under these fields (Figure 4, Figure S6) reveals the presence of a single peak for all investigated samples for which the maximum shifts towards higher temperature upon increasing the temperature, reflecting a field-induced slow relaxation. The fitting of the Cole-Cole plots with a generalized Debye model confirms the occurrence of a reasonable distribution of relaxation times with moderate values of the $\alpha$ parameter (i.e. $<0.2$; Table S5-S7, Figure S7). Based on these data, the relaxation time could be estimated to study the relaxation dynamics (Figure 5). 


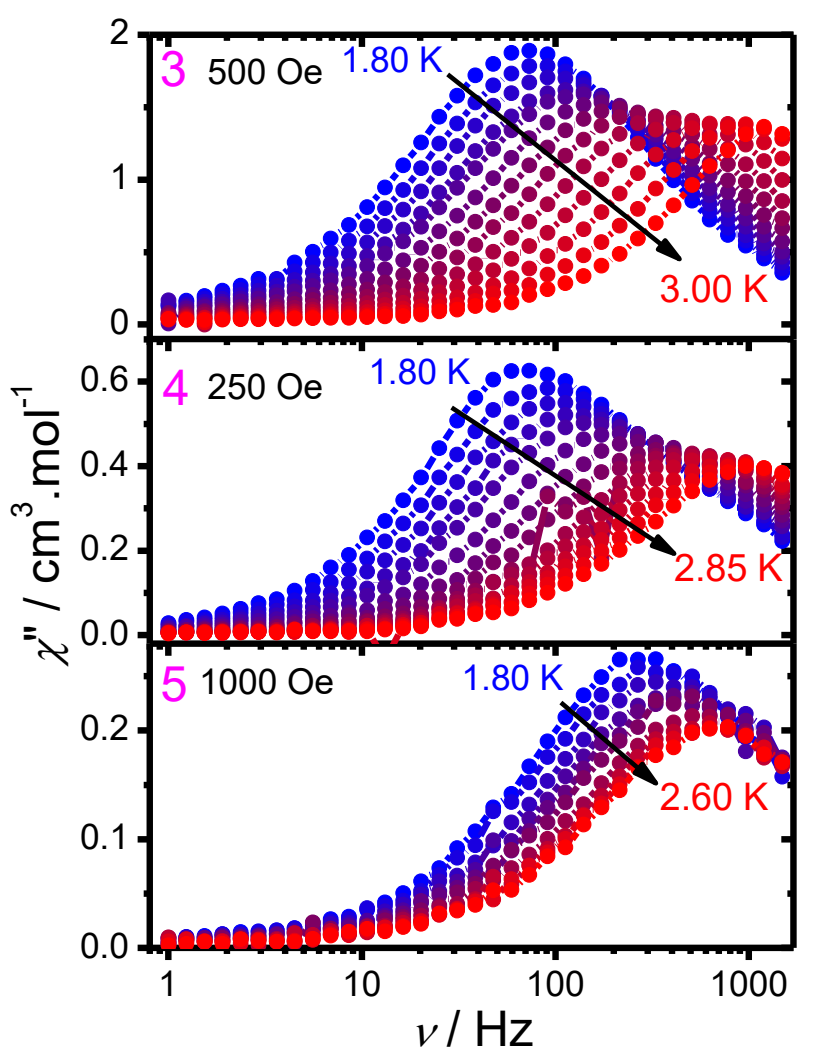

Figure 4. Frequency dependence of $\chi$ " for compounds 3-5 under the corresponding optimal dc fields

Attempts to model the whole data range using the following equation: $\tau^{-1}=\tau_{0}{ }^{-1} \exp (-\Delta / k T)+$ $C T^{n}+A T$ (Eq. 2, Table S8) has been performed. ${ }^{47}$ The first term accounts for a thermally activated process, while the second and third ones stand for two-phonon Raman and direct process, respectively. To avoid over-parameterization, the $n$ coefficient was fixed to different values until getting the best correlation coefficient. For $\mathbf{3}$, the best fitting gave unrealistic $\tau_{0}$ value suggesting that the Orbach process may not be involved. Hence, considering only Raman and direct processes $\left(\tau^{-1}=C T^{n}+A T\right.$, Eq. 3) gave a pertinent fit of the data (Table 2). As regards 4, while using Eq. 2 allows fitting correctly the data, a strong contribution from the Raman process suggests that the Orbach process is also not dominant. Finally, the fitting of the temperature dependence of the relaxation time for 5 could not be achieved using Eq. 2 while letting the $n$ 
parameter free in Eq. 3 leads to unrealistic parameters. Consequently, the $n$ parameter was fixed to different values until getting the best correlation coefficient (Table 2). Hence, it turns out that for all investigated compounds, the magnetization relaxes through a combination of Raman and direct processes. However, one can note different Raman coefficient exponent values suggesting different acoustic and optical phonons distributions. ${ }^{48}$

Table 2: Fit parameters of the temperature dependence of the relaxation time for 3-5.

\begin{tabular}{|l|l|l|l|}
\hline Compound & $n$ & $C\left(\mathrm{~s}^{-1} \cdot \mathrm{K}^{-n}\right)$ & $A\left(s^{-1} \cdot K^{-1}\right)$ \\
\hline $\mathbf{3}(500 \mathrm{Oe})$ & $11.7 \pm 0.3$ & $0.021 \pm 0.006$ & $302 \pm 19$ \\
\hline $\mathbf{4}(250 \mathrm{Oe})$ & $10.9 \pm 0.4$ & $0.06 \pm 0.03$ & $373 \pm 28$ \\
\hline $\mathbf{5}(1000 \mathrm{Oe})$ & $3.9^{*}$ & $98 \pm 5$ & $717 \pm 38$ \\
\hline
\end{tabular}

*fixed parameter

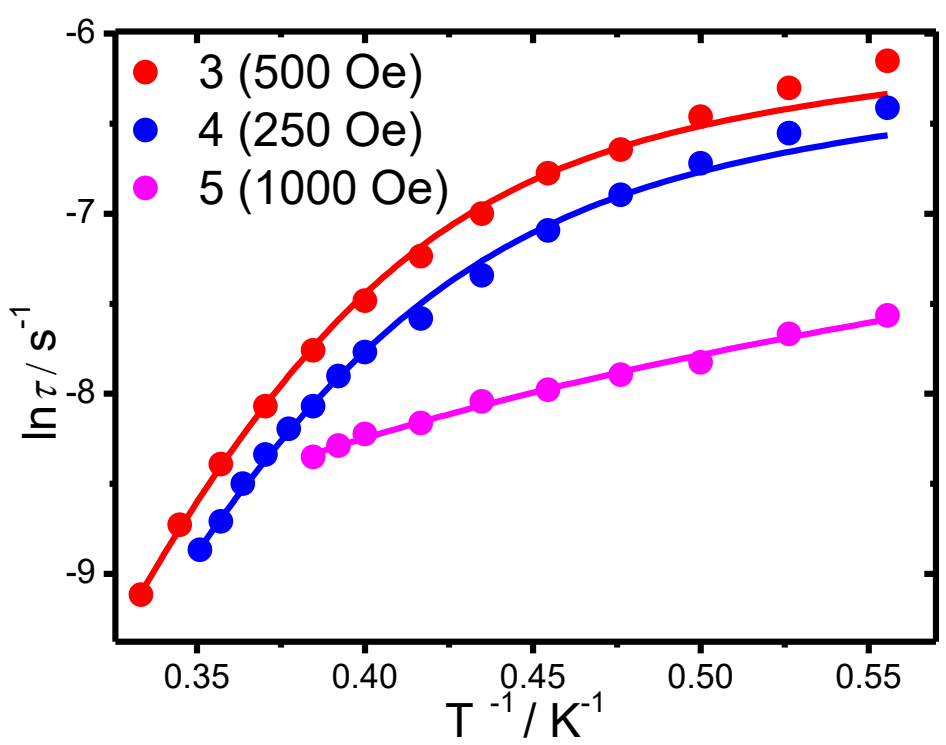

Figure 5. Temperature dependence of the relaxation time for 3-5 using the ac susceptibility data. The solid line represents the fit with Eq. 3.

Magneto-structural correlations. The observed results could be rationalized by simple electrostatic considerations and by analyzing the angular dependence the $4 f$ electronic density for 
the $\mathrm{Ln}^{3+}$ ions. ${ }^{49}$ The terbium analogue $\mathbf{2}$ is the only sample which does not exhibit a strong outof-phase component that would account for a slow relaxation of the magnetization, even in the presence of a dc field. This could be easily explained by its non-Kramers nature $\left({ }^{7} \mathrm{~F}_{6}\right.$ ground state) which requires a particular high symmetry in order to observe a slow relaxation of the magnetization. ${ }^{50}$ In contrast, $\mathrm{Dy}^{3+}, \mathrm{Er}^{3+}$ and $\mathrm{Yb}^{3+}$ are all Kramers ions, which ensure that the ground states will be doubly degenerate and allowed the possibility of the observation of the slow relaxation of the magnetization in not strictly axial or high symmetry complexes. However for compounds 3-5, in zero-dc field, the presence of the QTM prevents the observation of a slow relaxation of the magnetization. This QTM could be however suppressed by applying dc fields to permit the appearance of a field-induced SMM behavior. Indeed, $\mathrm{Dy}^{3+}$ presents an oblate electronic density requiring an axial crystal-field to enhance its anisotropy while $\operatorname{Er}^{3+}$ has a prolate one that necessitates an equatorial crystal-field. On the other hand, $\mathrm{Yb}^{3+}$ exhibits a prolate or oblate electronic density depending on the nature of the ground doublet. ${ }^{49}$ It appears therefore that the neutral tetradentate Tpma ligand in association with nitrates and the resulting lowsymmetry of the lanthanide site do not provide the requirements to maximize the anisotropy for either oblate or prolate lanthanide ions in zero dc field. Thus, the use of a static dc field appears necessary to reveal the slow relaxation. Such fact is confirmed by the determination of the anisotropic axes direction for the ground doublet with the MAGELLAN package for the dysprosium analogue $3 .{ }^{51}$ Hence, this axis is not found collinear to any specific dysprosiumligand bond and passes between the three nitrate moieties and the Tpma ligand (Figure S8). Interestingly, these results could be compared with those obtained from our recent investigations of the magnetic properties of nine-coordinate heteroleptic complexes $\left[\mathrm{Ln}(\mathrm{Tpm}) \mathrm{X}_{3}\right]\left(\mathrm{X}^{-}=\mathrm{NO}_{3}{ }^{-}\right.$, $\mathrm{Cl}^{-}$) based on the tridentate ligand tris(pyrazolyl)methane ligand (Tpm). ${ }^{24}$ In these systems, an 
anion dependence has been demonstrated depending on the oblate/prolate character of the lanthanide ion since a field-induced slow relaxation was only observed for the $\left[\mathrm{Dy}(\mathrm{Tpm})\left(\mathrm{NO}_{3}\right)_{3}\right]$ and the $\left[\mathrm{Er}(\mathrm{Tpm}) \mathrm{Cl}_{3}\right]$ analogue. In contrast, the Tpma ligand in association with nitrate moieties is able to provide a field-induced slow relaxation for both oblate $\left(\mathrm{Dy}^{3+}\right)$ and prolate $\left(\mathrm{Er}^{3+}\right)$, as well as for $\mathrm{Yb}^{3+}$ ion. Hence, the additional coordination of the tertiary amine with a quite long Ln-N distance (ranging from 2.709 to $2.774 \AA$ ) may affect the overall geometry and nitrate distribution favoring the slow relaxation of the magnetization with all Kramers ions.

Photoluminescence. The presence of Tpma, which might act as an antenna, directly coordinated to $\mathrm{Ln}^{3+}$ ions opens the possibility to observe a lanthanide-based luminescence and to design bifunctional luminescent SMMs. ${ }^{52-54}$ The luminescence properties of $\mathrm{Eu}^{3+}(\mathbf{1}), \mathrm{Tb}^{3+}(\mathbf{2})$ and $\mathrm{Dy}^{3+}$ (3) based complexes were investigated in the solid state at $295 \mathrm{~K}$. Complexes 1, 2 and $\mathbf{3}$ exhibit emission in red (1), green and yellow color regions respectively, when excited at $380 \mathrm{~nm}$ (Figure 6). As regards 1, emission peaks centered at 581, 593, $615(621,628), 650$, and $682(691,698$, 703) $\mathrm{nm}$ could be assigned to the infra $4 f$ transitions ${ }^{5} \mathrm{D}_{0} \rightarrow{ }^{7} \mathrm{~F}_{J}(J=0,1,2,3,4)$, respectively (Figure 6). The weak ${ }^{5} \mathrm{D}_{0} \rightarrow{ }^{7} \mathrm{~F}_{0} \mathrm{Eu}^{3+}$ ion transition observed at $581 \mathrm{~nm}$ confirms the low symmetry of the coordination environment of the $\mathrm{Eu}^{3+}$ site which is also reflected by the splitting of the ${ }^{5} \mathrm{D}_{0} \rightarrow{ }^{7} \mathrm{~F}_{2}$ and ${ }^{5} \mathrm{D}_{0} \rightarrow{ }^{7} \mathrm{~F}_{4}$ electronic dipole transitions, which are sensitive to the symmetry of the coordination environment. ${ }^{55}$ Similarly, the characteristic terbium-based luminescence could be observed for 2 with emission peaks centered at 491, 544 (551), 582 (596), 624, 653, 668 and $681 \mathrm{~nm}$, assigned to ${ }^{5} \mathrm{D}_{4} \rightarrow{ }^{7} \mathrm{~F}_{J}(J=6,5,4,3,2,1$, and 0$)$ transitions, respectively. On the other hand, the characteristic dysprosium-based emission peaks centered at 480, 574 and $663 \mathrm{~nm}$ for 3 could be assigned to ${ }^{4} \mathrm{~F}_{9 / 2} \rightarrow{ }^{6} \mathrm{H}_{15 / 2},{ }^{4} \mathrm{~F}_{9 / 2} \rightarrow{ }^{6} \mathrm{H}_{13 / 2}$ and ${ }^{4} \mathrm{~F}_{9 / 2} \rightarrow{ }^{6} \mathrm{H}_{11 / 2}$ transitions (Figure 6). 
For all complexes, the absence of a broad emission originating from the Tpma ligand suggests either an efficient energy transfer from this ligand to the lanthanide ion or a direct excitation of the lanthanide through the $f-f$ transitions. Analysis of the excitation spectra for complexes $\mathbf{1}, \mathbf{2}$ and 3 (Figures S9-S11) monitored into the emission bands at 593, 543 and $574 \mathrm{~nm}$, respectively, shows the typical sharp lines related to direct intra $f-f$ transitions. ${ }^{56-58}$ Consequently, the absence of broad bands related to the organic ligand in the excitation spectra clearly points out a direct sensitization of the lanthanide ion through $f-f$ transitions rather than an energy transfer involving the Tpma moieties. ${ }^{59-61}$ Thus, although it does not act a sensitizer, the Tpma ligand does not quench the lanthanide luminescence.

In order to get further details, the photoluminescence emission decay of complexes $\mathbf{1 , 2}$ and $\mathbf{3}$ in the solid state at $295 \mathrm{~K}$ was performed to determine the luminescence lifetimes. These later are found equal to $1.51,1.77$ and $0.022 \mathrm{~ms}$ for $\mathbf{1}, \mathbf{2}$ and $\mathbf{3}$ respectively (Figs. S12-S14), which are typical values for europium, terbium and dysprosium complexes. ${ }^{55,62-65}$ 


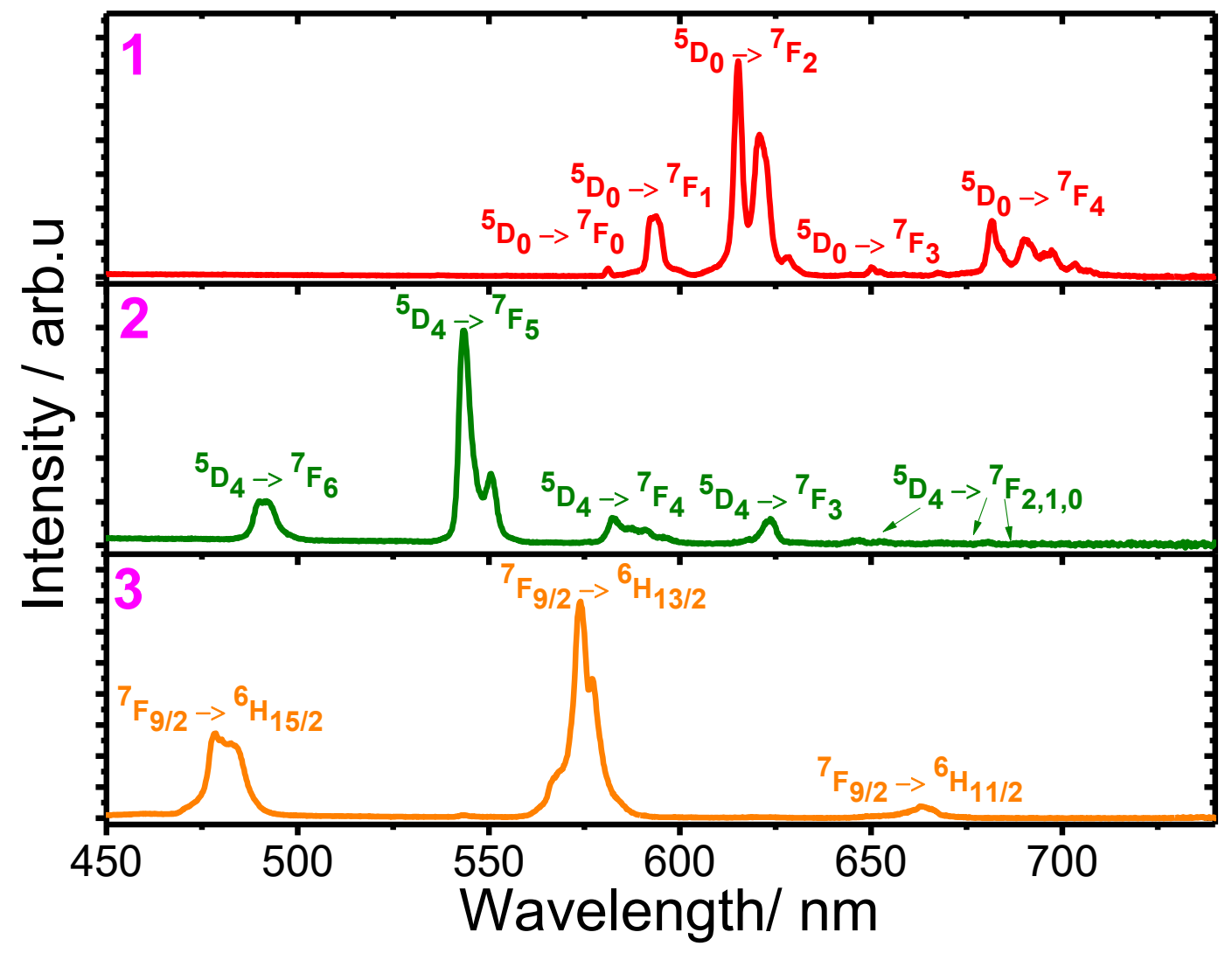

Figure 6. Solid-state luminescence spectra $\left(\lambda_{\mathrm{exc}}=380 \mathrm{~nm}\right)$ for $\mathbf{1}, \mathbf{2}$ and $\mathbf{3}$ at room temperature.

\section{Conclusions}

A series of heteroleptic lanthanide complexes based on an original tetradentate tripodal ligand has been described. While the $\mathrm{Eu}^{3+}, \mathrm{Tb}^{3+}, \mathrm{Dy}^{3+}$ and $\mathrm{Er}^{3+}$ complexes are found isostructural, the $\mathrm{Yb}^{3+}$ analogue presents a different structure due to the reduction of the coordination number through different coordination of one of the nitrates. Among this series, the complexes based on Kramers ions $\left(\mathrm{Dy}^{3+}, \mathrm{Er}^{3+}\right.$ and $\left.\mathrm{Yb}^{3+}\right)$ exhibit a field-induced SMM behavior involving a relaxation through Raman and direct processes. On the contrary, the complex based on the non-Kramers $\mathrm{Tb}^{3+}$ ion does not present a slow relaxation. In contrast to the complexes based on a related tridentate trispyrazolylmethane ligand, ${ }^{24}$ these results suggest that the Tmpa ligand in association with nitrate moieties stabilize either the prolate or oblate electronic densities of the lanthanide 
ions. This clearly highlights that the fine tuning of the coordination allows the adjustment of the slow relaxation features. In addition, the Tmpa ligand does not act as luminescence quencher since a clear lanthanide-based photoluminescence could be detected for the $\mathrm{Eu}^{3+}, \mathrm{Tb}^{3+}$ and Dy $^{3+}$ complexes through a direct $f-f$ excitation. The dysprosium complex 3 could be therefore viewed as a bifunctional complex showing a field-induced slow relaxation and lanthanide luminescence. The great tunability of these tripodal ligands, in terms of steric and electronic factors, could be taken as an advantage to in fine enhance the slow relaxation and photoluminescence features.

\section{ASSOCIATED CONTENT}

\section{Supporting Information.}

Additional crystallographic parameters, magnetic and photoluminescence data. The following files are available free of charge.

\section{AUTHOR INFORMATION}

\section{Corresponding Author}

*E-mail: jerome.long@umontpellier.fr

*E-mail: trif@iomc.ras.ru

\section{Author Contributions}

The manuscript was written through contributions of all authors. All authors have given approval to the final version of the manuscript.

\section{ACKNOWLEDGMENT}


The authors thank the University of Montpellier, CNRS for financial support, PAC of ICGM for magnetic measurements. The Russian co-authors thank the Russian Science Foundation (grant 17-73-30036).

\section{REFERENCES}

(1) Luzon, J.; Sessoli, R., Lanthanides in molecular magnetism: so fascinating, so challenging. Dalton Trans. 2012, 41, 13556-13567.

(2) Woodruff, D. N.; Winpenny, R. E. P.; Layfield, R. A., Lanthanide single-molecule magnets. Chem. Rev. 2013, 113, 5110-5148.

(3) Troiani, F.; Affronte, M., Molecular spins for quantum information technologies. Chem. Soc. Rev. 2011, 40, 3119-3129.

(4) Bogani, L.; Wernsdorfer, W., Molecular spintronics using single-molecule magnets. Nat. Mater. 2008, 7, 179-186.

(5) Tang, J.; Zhang, P., Lanthanide Single-Ion Molecular Magnets. In Lanthanide Single Molecule Magnets, Springer Berlin Heidelberg: Berlin, Heidelberg, 2015; pp 41-90.

(6) Layfield, R. A.; Murugesu, M., Lanthanides and Actinides in Molecular Magnetism. ed.; Wiley: 2015.

(7) Ungur, L.; Chibotaru, L. F., Strategies toward High-Temperature Lanthanide-Based Single-Molecule Magnets. Inorg. Chem. 2016, 55, 10043-10056.

(8) Lunghi, A.; Totti, F.; Sessoli, R.; Sanvito, S., The role of anharmonic phonons in underbarrier spin relaxation of single molecule magnets. Nat. Comm. 2017, 8, 14620.

(9) Escalera-Moreno, L.; Baldoví, J. J.; Gaita-Ariño, A.; Coronado, E., Spin states, vibrations and spin relaxation in molecular nanomagnets and spin qubits: a critical perspective. Chem. Sci. 2018, 9, 3265-3275.

(10) Liu, J.; Chen, Y.-C.; Liu, J.-L.; Vieru, V.; Ungur, L.; Jia, J.-H.; Chibotaru, L. F.; Lan, Y.; Wernsdorfer, W.; Gao, S.; Chen, X.-M.; Tong, M.-L., A Stable Pentagonal Bipyramidal Dy(III) Single-Ion Magnet with a Record Magnetization Reversal Barrier over 1000 K. J. Am. Chem. Soc. 2016, 138, 5441-5450.

(11) Gupta, S. K.; Rajeshkumar, T.; Rajaraman, G.; Murugavel, R., An air-stable Dy(iii) single-ion magnet with high anisotropy barrier and blocking temperature. Chem. Sci. 2016, 7 , 5181-5191.

(12) Guo, F. S.; Day, B. M.; Chen, Y. C.; Tong, M. L.; Mansikkamaki, A.; Layfield, R. A., A Dysprosium Metallocene Single-Molecule Magnet Functioning at the Axial Limit. Angew. Chem. Int. Ed. Engl. 2017, 56, 11445-11449.

(13) Ding, Y.-S.; Chilton, N. F.; Winpenny, R. E. P.; Zheng, Y.-Z., On Approaching the Limit of Molecular Magnetic Anisotropy: A Near-Perfect Pentagonal Bipyramidal Dysprosium(III) Single-Molecule Magnet. Angew. Chem. Int. Edit. 2016, 55, 16071-16074.

(14) Goodwin, C. A. P.; Ortu, F.; Reta, D.; Chilton, N. F.; Mills, D. P., Molecular magnetic hysteresis at 60 kelvin in dysprosocenium. Nature 2017, 548, 439-442.

(15) Randall McClain, K.; Gould, C. A.; Chakarawet, K.; Teat, S. J.; Groshens, T. J.; Long, J. R.; Harvey, B. G., High-temperature magnetic blocking and magneto-structural correlations in a 
series of dysprosium(iii) metallocenium single-molecule magnets. Chem. Sci. 2018, 9, 84928503.

(16) Guo, F.-S.; Day, B. M.; Chen, Y.-C.; Tong, M.-L.; Mansikkamäki, A.; Layfield, R. A., Magnetic hysteresis up to 80 kelvin in a dysprosium metallocene single-molecule magnet. Science 2018, 362, 1400-1403.

(17) Ding, Y. S.; Chilton, N. F.; Winpenny, R. E.; Zheng, Y. Z., On Approaching the Limit of Molecular Magnetic Anisotropy: A Near-Perfect Pentagonal Bipyramidal Dysprosium(III) Single-Molecule Magnet. Angew. Chem., Int. Ed. Engl. 2016, 55, 16071-16074.

(18) Chen, Y.-C.; Liu, J.-L.; Ungur, L.; Liu, J.; Li, Q.-W.; Wang, L.-F.; Ni, Z.-P.; Chibotaru, L. F.; Chen, X.-M.; Tong, M.-L., Symmetry-Supported Magnetic Blocking at $20 \mathrm{~K}$ in Pentagonal Bipyramidal Dy(III) Single-Ion Magnets. J. Am. Chem. Soc. 2016, 138, 2829-2837.

(19) Meng, Y.-S.; Xu, L.; Xiong, J.; Yuan, Q.; Liu, T.; Wang, B.-W.; Gao, S., LowCoordinate Single-Ion Magnets by Intercalation of Lanthanides into a Phenol Matrix. Angew. Chem. Int. Edit. 2018, 57, 4673-4676.

(20) Long, J.; Basalov, I. V.; Forosenko, N. V.; Lyssenko, K. A.; Mamontova, E.; Cherkasov, A. V.; Damjanović, M.; Chibotaru, L. F.; Guari, Y.; Larionova, J.; Trifonov, A. A., Dysprosium Single-Molecule Magnets with Bulky Schiff-base Ligands: Modification of the Slow Relaxation of the Magnetization by Substituent Change. Chem. Eur. J. 2019, 25, 474-478.

(21) Ding, Y. S.; Han, T.; Zhai, Y. Q.; Reta, D.; Chilton, N. F.; Winpenny, R. E. P.; Zheng, Y. Z., A Study of Magnetic Relaxation in Dysprosium(III) Single-Molecule Magnets. Chem. Eur. J. 2020, 26, 5893-5902.

(22) Canaj, A. B.; Dey, S.; Martí, E. R.; Wilson, C.; Rajaraman, G.; Murrie, M., Insight into D6h Symmetry: Targeting Strong Axiality in Stable Dysprosium(III) Hexagonal Bipyramidal Single-Ion Magnets. Angew. Chem. Int. Edit. 2019, 58, 14146-14151.

(23) Li, Z.-H.; Zhai, Y.-Q.; Chen, W.-P.; Ding, Y.-S.; Zheng, Y.-Z., Air-Stable Hexagonal Bipyramidal Dysprosium(III) Single-Ion Magnets with Nearly Perfect D6h Local Symmetry. Chem. Eur. J. 2019, 25, 16219-16224.

(24) Long, J.; Lyubov, D.; Mahrova, T.; Cherkasov, A.; Fukin, G. K.; Guari, Y.; Larionova, J.; Trifonov, A., Synthesis, structure and magnetic properties of tris(pyrazolyl)methane lanthanide complexes: effect of the anion over the slow relaxation of the magnetization. Dalton Trans. 2018, 47, 5153-5156.

(25) Xu, G.-F.; Wang, Q.-L.; Gamez, P.; Ma, Y.; Clérac, R.; Tang, J.; Yan, S.-P.; Cheng, P.; Liao, D.-Z., A promising new route towards single-molecule magnets based on the oxalate ligand. Chem. Commun. 2010, 46, 1506-1508.

(26) Xu, G.-F.; Gamez, P.; Tang, J.; Clérac, R.; Guo, Y.-N.; Guo, Y., MIIIDyIII3 (M = FeIII, CoIII) Complexes: Three-Blade Propellers Exhibiting Slow Relaxation of Magnetization. Inorg. Chem. 2012, 51, 5693-5698.

(27) Guégan, F.; Riobé, F.; Maury, O.; Jung, J.; Le Guennic, B.; Morell, C.; Luneau, D., Teaching an old molecule new tricks: evidence and rationalisation of the slow magnetisation dynamics in [DyTp2Acac]. Inorg. Chem. Front. 2018, 5, 1346-1353.

(28) Zhang, P.; Perfetti, M.; Kern, M.; Hallmen, P. P.; Ungur, L.; Lenz, S.; Ringenberg, M. R.; Frey, W.; Stoll, H.; Rauhut, G.; van Slageren, J., Exchange coupling and single molecule magnetism in redox-active tetraoxolene-bridged dilanthanide complexes. Chem. Sci. 2018, 9, 1221-1230. 
(29) Norel, L.; Darago, L. E.; Le Guennic, B.; Chakarawet, K.; Gonzalez, M. I.; Olshansky, J. H.; Rigaut, S.; Long, J. R., A Terminal Fluoride Ligand Generates Axial Magnetic Anisotropy in Dysprosium Complexes. Angew. Chem. Int. Edit. 2018, 57, 1933-1938.

(30) Machado, K.; Mukhopadhyay, S.; Videira, R. A.; Mishra, J.; Mobin, S. M.; Mishra, G. S., Polymer encapsulated scorpionate Eu3+ complexes as novel hybrid materials for high performance luminescence applications. RSC Adv. 2015, 5, 35675-35682.

(31) Driessen, W. L.; Wiesmeijer, W. G. R.; Schipper-Zablotskaja, M.; De Graaff, R. A. G.; Reedijk, J., Transition metal coordination compounds of two pyrazole-substituted ammonia ligands. X-ray structure of [Biss(1-pyrazolylmethyl)aminecobalt(II)] bis(nitrate). Inorg. Chim. Acta 1989, 162, 233-238.

(32) Blackman, A. G., The coordination chemistry of tripodal tetraamine ligands. Polyhedron 2005, 24, 1-39.

(33) Haldón, E.; Delgado-Rebollo, M.; Prieto, A.; Álvarez, E.; Maya, C.; Nicasio, M. C.; Pérez, P. J., Synthesis, Structural Characterization, Reactivity, and Catalytic Properties of Copper(I) Complexes with a Series of Tetradentate Tripodal Tris(pyrazolylmethyl)amine Ligands. Inorg. Chem. 2014, 53, 4192-4201.

(34) Goswami, S.; Biswas, S.; Tomar, K.; Konar, S., Tuning the Magnetoluminescence Behavior of Lanthanide Complexes Having Sphenocorona and Cubic Coordination Geometries. Eur. J. Inorg. Chem. 2016, 2016, 2774-2782.

(35) Guo, F.-S.; Day, B. M.; Chen, Y.-C.; Tong, M.-L.; Mansikkamäki, A.; Layfield, R. A., A Dysprosium Metallocene Single-Molecule Magnet Functioning at the Axial Limit. Angew. Chem. Int. Edit. 2017, 56, 11445-11449.

(36) Kachi-Terajima, C.; Yanagi, K.; Kaziki, T.; Kitazawa, T.; Hasegawa, M., Luminescence tuning of imidazole-based lanthanide(iii) complexes [ $\mathrm{Ln}=\mathrm{Sm}, \mathrm{Eu}, \mathrm{Gd}, \mathrm{Tb}, \mathrm{Dy}]$. Dalton Trans. 2011, 40, 2249-2256.

(37) Molloy, J. K.; Philouze, C.; Fedele, L.; Imbert, D.; Jarjayes, O.; Thomas, F., Sevencoordinate lanthanide complexes with a tripodal redox active ligand: structural, electrochemical and spectroscopic investigations. Dalton Trans. 2018, 47, 10742-10751.

(38) Pedersen, K. S.; Dreiser, J.; Weihe, H.; Sibille, R.; Johannesen, H. V.; Sørensen, M. A.; Nielsen, B. E.; Sigrist, M.; Mutka, H.; Rols, S.; Bendix, J.; Piligkos, S., Design of SingleMolecule Magnets: Insufficiency of the Anisotropy Barrier as the Sole Criterion. Inorg. Chem. 2015, 54, 7600-7606.

(39) Lucaccini, E.; Sorace, L.; Perfetti, M.; Costes, J.-P.; Sessoli, R., Beyond the anisotropy barrier: slow relaxation of the magnetization in both easy-axis and easy-plane Ln(trensal) complexes. Chem. Commun. 2014, 50, 1648-1651.

(40) Perfetti, M.; Lucaccini, E.; Sorace, L.; Costes, J. P.; Sessoli, R., Determination of Magnetic Anisotropy in the LnTRENSAL Complexes ( $\mathrm{Ln}=\mathrm{Tb}, \mathrm{Dy}$, Er) by Torque Magnetometry. Inorg. Chem. 2015, 54, 3090-3092.

(41) Craze, A. R.; Huang, X.-D.; Etchells, I.; Zheng, L.-M.; Bhadbhade, M. M.; Marjo, C. E.; Clegg, J. K.; Moore, E. G.; Avdeev, M.; Lindoy, L. F.; Li, F., Synthesis and characterisation of new tripodal lanthanide complexes and investigation of their optical and magnetic properties. Dalton Trans. 2017, 46, 12177-12184.

(42) Lyle, S. J.; Rahman, M. M., Complexometric titration of yttrium and the lanthanons-I. Talanta 1963, 10, 1177-1182.

(43) Casanova, D.; Llunell, M.; Alemany, P.; Alvarez, S., The Rich Stereochemistry of EightVertex Polyhedra: A Continuous Shape Measures Study. Chem. Eur. J. 2005, 11, 1479-1494. 
(44) Van Vleck, J. H., The theory of electric and magnetic susceptibilities. ed.; Clarendon Press: 1932.

(45) Orbach, R.; Blume, M., Spin-Lattice Relaxation in Multilevel Spin Systems. Phys. Rev. Lett. 1962, 8, 478-480.

(46) Shrivastava, K. N., Theory of Spin-Lattice Relaxation. physica status solidi (b) 1983, $117,437-458$.

(47) Meihaus, K. R.; Minasian, S. G.; Lukens, W. W.; Kozimor, S. A.; Shuh, D. K.; Tyliszczak, T.; Long, J. R., Influence of pyrazolate vs N-heterocyclic carbene ligands on the slow magnetic relaxation of homoleptic trischelate lanthanide(III) and uranium(III) complexes. $J$. Am. Chem. Soc. 2014, 136, 6056-6068.

(48) Liddle, S. T.; van Slageren, J., Improving f-element single molecule magnets. Chem. Soc. Rev. 2015, 44, 6655-6669.

(49) Rinehart, J. D.; Long, J. R., Exploiting single-ion anisotropy in the design of f-element single-molecule magnets. Chem. Sci. 2011, 2, 2078-2085.

(50) Ishikawa, N.; Sugita, M.; Ishikawa, T.; Koshihara, S.; Kaizu, Y., Mononuclear lanthanide complexes with a long magnetization relaxation time at high temperatures: A new category of magnets at the single-molecular level. J. Phys. Chem. B 2004, 108, 11265-11271.

(51) Chilton, N. F.; Collison, D.; McInnes, E. J. L.; Winpenny, R. E. P.; Soncini, A., An electrostatic model for the determination of magnetic anisotropy in dysprosium complexes. Nat. Commun. 2013, 4, 2551.

(52) Pointillart, F.; le Guennic, B.; Cador, O.; Maury, O.; Ouahab, L., Lanthanide Ion and Tetrathiafulvalene-Based Ligand as a "Magic" Couple toward Luminescence, Single Molecule Magnets, and Magnetostructural Correlations. Acc. Chem. Res. 2015, 48, 2834-2842.

(53) Jia, J.-H.; Li, Q.-W.; Chen, Y.-C.; Liu, J.-L.; Tong, M.-L., Luminescent single-molecule magnets based on lanthanides: Design strategies, recent advances and magneto-luminescent studies. Coord. Chem. Rev. 2019, 378, 365-381.

(54) Long, J.; Guari, Y.; Ferreira, R. A. S.; Carlos, L. D.; Larionova, J., Recent advances in luminescent lanthanide based Single-Molecule Magnets. Coord. Chem. Rev. 2018, 363, 57-70.

(55) Bünzli, J.-C. G.; Eliseeva, S. V., Basics of Lanthanide Photophysics. In Lanthanide Luminescence: Photophysical, Analytical and Biological Aspects, Hänninen, P.; Härmä, H., Eds. Springer Berlin Heidelberg: Berlin, Heidelberg, 2011; pp 1-45.

(56) Carnall, W. T.; Fields, P. R.; Rajnak, K., Electronic Energy Levels of the Trivalent Lanthanide Aquo Ions. IV. Eu3+. J. Chem. Phys. 1968, 49, 4450-4455.

(57) Carnall, W. T.; Fields, P. R.; Rajnak, K., Electronic Energy Levels of the Trivalent Lanthanide Aquo Ions. III. Tb3+. J. Chem. Phys. 1968, 49, 4447-4449.

(58) Kumar, K. N.; Padma, R.; Ratnakaram, Y. C.; Kang, M., Bright green emission from fMWCNT embedded co-doped Bi3 $++\mathrm{Tb} 3+$ :polyvinyl alcohol polymer nanocomposites for photonic applications. RSC Adv. 2017, 7, 15084-15095.

(59) Hänninen, P.; Härmä, H., Lanthanide luminescence: photophysical, analytical and biological aspects. ed.; Springer Science \& Business Media: 2011; Vol. 7.

(60) de Bettencourt-Dias, A., Luminescence of lanthanide ions in coordination compounds and nanomaterials. ed.; John Wiley \& Sons: 2014.

(61) Bünzli, J.-C. G., Lanthanide Luminescence for Biomedical Analyses and Imaging. Chem. Rev. 2010, 110, 2729-2755.

(62) Bunzli, J. C. G.; Piguet, C., Taking advantage of luminescent lanthanide ions. Chem. Soc. Rev. 2005, 34, 1048-1077. 
(63) Eliseeva, S. V.; Bünzli, J.-C. G., Lanthanide luminescence for functional materials and bio-sciences. Chem. Soc. Rev. 2010, 39, 189-227.

(64) Bunzli, J. C. G.; Pecharsky, V. K., Handbook on the Physics and Chemistry of Rare Earths: Including Actinides. ed.; Elsevier Science: 2016.

(65) Carlos, L. D.; Ferreira, R. A. S.; de Zea Bermudez, V.; Ribeiro, S. J. L., Lanthanidecontaining light-emitting organic-inorganic hybrids: A bet on the future. Adv. Mater. 2009, 21, 509-534. 


\section{For Table of Contents Use Only}

Heteroleptic lanthanide complexes coordinated by tripodal tetradentate ligand: synthesis, structure, magnetic and photoluminescent properties

Jérôme Long ${ }^{* a}$ Dmitry M. Lyubov, Tatyana V. Mahrova, Konstantin A. Lyssenko, Alexander A. Korlyukov, Yury V. Fedorov, Ekaterina Yu. Chernikova, Yannick Guari, Joulia Larionova, and Alexander A. Trifonov*

Field-induced SMM and luminescence in lanthanide complexes based on a tripodal tetradentate ligand

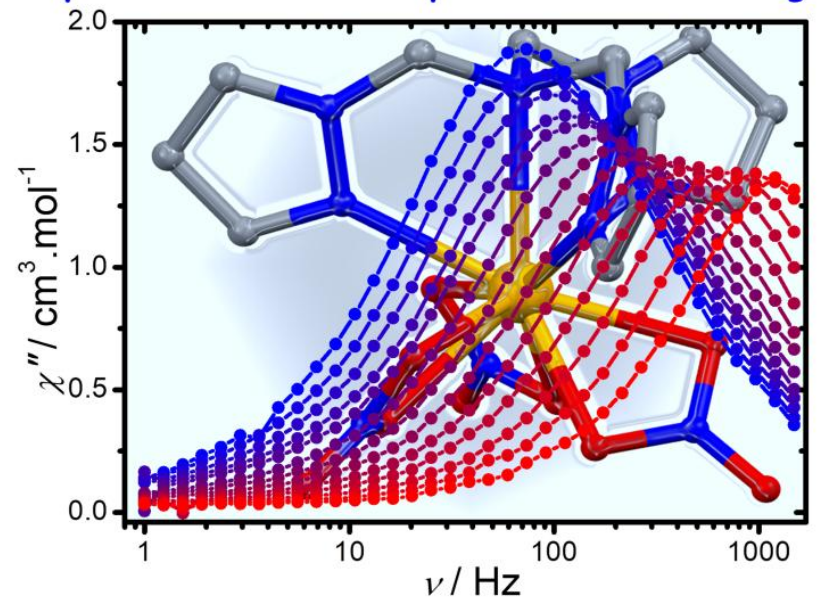

A series of lanthanide complexes based on a tripodal tetradentate ligand $\left[\mathrm{Ln}(\mathrm{Tpma})\left(\mathrm{NO}_{3}\right)_{3}\right] \cdot n \mathrm{MeCN}$ is reported. The europium, terbium and dysprosium analogues exhibit a lanthanide-based luminescence, while dysprosium, erbium and ytterbium compounds show a field-induced slow relaxation of their magnetization. 